\title{
STRESS AND DEPRESSION IN THE EXCLUSION OF THE COVID-19 PANDEMIC IN GREEK UNIVERSITY STUDENTS
}

\author{
Georgia Konstantopoulou'1, \\ Stavroula Pantazopoulou ${ }^{2}$, \\ Theodoros Iliou ${ }^{3}$, \\ Natassa Raikou ${ }^{4}$ \\ ${ }^{1}$ Special Office for Health Consulting Services and \\ Department of Education and Social Work, \\ School of Humanities and Social Sciences, \\ University of Patras, University of Patras Rion Campus, \\ Rion Patras, 26504 Patras, \\ Greece \\ ${ }^{2}$ Department of Psychology \\ University of Crete \\ Rethymnon, Crete, 74100, \\ Greece \\ ${ }^{3}$ Medical Informatics Laboratory, \\ Department of Medicine, School of Health Sciences, \\ Democritus University of Thrace, \\ Alexandroupolis Campus, \\ 6th km Alexadroupolis - Makris (Dragana), Alexandroupolis, \\ Greece \\ ${ }^{4}$ Department of Educational Sciences and Early Childhood Education, \\ School of Humanities and Social Sciences, University of Patras, \\ University of Patras Rion Campus, \\ Rion Patras, 26504 Patras,
} Greece

\begin{abstract}
:
With the advent of the new corona virus, all aspects of our daily lives have changed radically, adding great weight to the physical and psychological well-being of all of us, but even more so of students, having to deal with the stress of separation and separation. The aim of the current study was to measure the psychological impact of the new viral disease (COVID-19) on the symptoms of stress and depression in the Greek student population and to determine the possible clinical correlations. 1140 students of the University of Patras participated and $68.0 \%$ of the participants reported moderate subclinical anxiety symptoms, which means that the Covid-19 virus initially seemed to affect the stress levels of the students, while $32.3 \%$ of the students reported moderate
\end{abstract}

i Correspondence: email gkonstantop@upatras.gr 
depression symptoms. Student stress seems to be due to the gradually increasing distances between people resulting from quarantine.

Keywords: COVID-19, university students, stress, depression, psychological impact, SSQ-25, Subclinical Stress Symptom Questionnaire, BDI, Beck Depression Inventory, IES$\mathrm{R}$, the Impact of Event Scale - Revised

\section{Introduction}

In the city of Wuhan, Hubei province, China, a series of cases of pneumonia occurred. On January 9, 2020, the Chinese health authorities announced that it is a new corona strain (2019-nCoV). Corona viruses are a group of viruses that usually cause respiratory infections of varying severity in humans and animals. It is estimated that about one-third of upper respiratory infections in humans can be caused by corona viruses (National Public Health Organization, 2020). The National Agency for Public Health (EODY) is monitoring developments from the beginning and is in constant contact with both the European Center for Disease Control and Prevention (ECDC) and the World Health Organization (WHO). The Ministry of Health announced that the outbreak of the COVID19 virus in Greece has suspended all educational institutions in the country on March 11, 2020 for precautionary reasons, in order to reduce the spread of coronavirus in the country. As reported in the media, the measure of universal closure of schools was deemed to have been taken early to have the maximum value (Skai News, 2020).

This sudden closure led to a crisis in education systems in Greece and worldwide and an effort was made to respond immediately to the emergency in which education could not fulfill its function (Karalis, 2020). Especially for higher education, the State responded immediately and provided the opportunity to all universities in the country to move teaching online; amending the legal framework for the exceptional circumstances (Karalis \& Raikou, 2020). This immediate reaction and the adjustment described met with the students' acceptance, according to the available data (University of Patras Covid-19 Committee, 2020).

Quarantine has been used for centuries in an effort to prevent the introduction, transmission and spread of communicable diseases (Barbisch, Koenig, \& Shih, 2015). Instructions have been announced for students in our country as well. Students should avoid gatherings and congestion anywhere (e.g. cafes, cinemas), avoid group extracurricular activities, not meet at friends' houses, restaurants or shopping malls, and continue their educational activities remotely ( e-learning), to avoid contact with people belonging to vulnerable groups, to wash hands frequently and well with soap and water or an alcoholic solution, to avoid close contact (handshakes, hugs and kisses) and in case of symptoms, stay at home and contact a doctor or the National Agency for Public Health (EODY) (Centers for Disease Control and Prevention, 2020). Experts pointed out that the measures should be adapted for vulnerable populations, such as the elderly, immigrants, people with mental health problems (Williams, 2020). They may also not have access to 
health care due to quarantine restriction (Yang et al., 2020). In emergencies or times of crisis, mental health services, or more broadly, medical systems, are deficient (Liu et al., 2020).

Students experience stress and depression during their student life, due to the pressure they face, find it difficult to organize and manage their work, set goals and set priorities, face and experience emotional difficulties. Many studies show that they may have more psychopathological issues than other people of the same age (Bayram \& Bilgel, 2008; Eisenberg et al., 2007; Sawatzky, 1998). This is because, while adults, their study suspends the process of independence and confronts them with issues of identity, socialization, integration into professional life, renegotiation of relationships and conflict with ideologies and standards, i.e. they go through a period of transition (Bayram \& Bilgel, 2008; Konstantopoulou \& Raikou, 2020).

At the same time, studies as an educational process can be a particularly stressful event for some students, as it is a challenge to achieve goals - academic and professional - but also to manage issues of separation from the family (Papadioti-Athanasiou \& Kaltsouda, 2007). Especially now that they are facing changes in their studies, an unfavorable environment of limited social contacts, incarceration, financial insecurity, psychological effects and the emergence of psychiatric illness are critical as they require immediate detection and management. In China, $24.9 \%$ of college students experience anxiety due to this COVID-19 pandemic. Living in urban areas, living with parents, and having a stable family income were protective factors for students from experienced stress during the COVID-19 epidemic. However, having a relative or acquaintance infected with COVID-19 was an independent risk factor for experiencing stress.

Stress related to COVID-19 that included financial stress affect daily life and academic delays were positively correlated with the level of stress symptoms. Students' mental health is significantly affected when dealing with public health emergencies and requires the attention, help and support of society, families and colleges (Cao et al., 2020). Students are shown to have even more stress in the middle of a pandemic, symptoms of discomfort and abandonment of their academic obligations (Grubic et al., 2020). The University of Patras, understanding the difficulties of incarceration and social isolation during the restrictive measures to prevent COVID-19, provides students with remote psychological support and counseling (University of Patras, 2020). We believe that the recording of student psychology during the COVID-19 pandemic is important in order to outline the psychology of students, which will contribute to the proper and timely preparation of psychological support centers to meet their immediate needs.

\section{Objective and Methods}

The aim of the study is to record the psychology of students of the University of Patras during the COVID-19 pandemic. An online survey was conducted by the Department of Education and Social Work, the Department of Preschool Education and Training of the University of Patras and the Special Office for Health Services of the University of Patras 
from April 13, 2020 to March 2. The survey was approved by the Council of the Department of Education and Social Work and included a set of questions about demographic data, a questionnaire for subclinical stress symptoms SS Q-25 on the COVID19 pandemic, its impact, the Incident Scale Review Detects Symptoms of PostTraumatic Stress Disorder (PTSD) associated with a specific event, and the BECK Depression Scale (BDI) that measures depressive symptoms.

A. SSQ-25, Subclinical Stress Symptom Questionnaire (Helms, Wetzel, \& Weierstall, 2017). This self-report instrument measures psychological and physiological stress symptoms on 25 items answered on a 5-point Likert-type scale ranging from 1 (not at all) to 5 (very strong). Subjects report on this scale if and to what extent they have experienced any of the symptoms within the last four weeks. The psychological stress dimension consists of 15 items concerning inner tension, nervousness, concentration issues, and worries (e.g., "I felt lost or lonely among people"). The physiological stress dimension is assessed with 10 items targeting aches and pains, weight changes, circulatory problems, and insomnia (e.g., "I had palpitation or breathing difficulties").

B. BDI, Beck Depression Inventory (Beck, 1972), created by Aaron T. Beck, is a 21question multiple-choice self-report inventory, one of the most widely used psychometric tests for measuring the severity of depression. Its development marked a shift among mental health professionals, who had until then, viewed depression from a psychodynamic perspective, instead of it being rooted in the patient's own thoughts. BDI consisted of twenty-one questions about how the subject has been feeling in the last week. Each question had a set of at least four possible responses, ranging in intensity. For example: (0) I do not feel sad, (1) I feel sad, (2) I am sad all the time and I can't snap out of it, (3) I am so sad or unhappy that I can't stand it.

C. IES-R, the Impact of Event Scale - Revised (McCabe, D., 2019) is a short, easily administered self-report questionnaire, has 22 questions, 5 of which were added to the original Horowitz (IES) to better capture the American Psychiatric Association. Diagnostic and Statistical Manual of Mental Disorders (DSM) criteria for PTSD (Weiss \& Marmar, 1997). The tool, not diagnostic for PTSD, is an appropriate instrument to measure the subjective response to a specific traumatic event in the older adult population, especially in the response sets of intrusion (intrusive thoughts, nightmares, intrusive feelings and imagery, dissociative-like re-experiencing), avoidance (numbing of responsiveness, avoidance of feelings, situations, and ideas), and hyperarousal (anger, irritability, hypervigilance, difficulty concentrating, heightened startle), as well as a total subjective stress IES-R score. The IES-R is not meant to be diagnostic. While there is no specific cut-off score, scores higher than 24 are of concern the higher the score the greater the concern for PTSD and associated health and well-being consequences. The IES-R revises the original IES, recognized as one of the earliest self-report tools developed to assess for post-traumatic stress, to add a third cluster of symptoms, hyperarousal, to 
intrusion and avoidance subscales. IES- $\mathrm{R}$ is the acronym for the test assessment purpose: I - Impact, E - of Event, S - Scale, R - Revised (Asukai et al., 2002).

Data were analyzed with SPSS Edition 22.0. and analyzed the descriptive statistics conducted to illustrate the demographic and other selected characteristics of the respondents, such as symptoms of subclinical stress, symptoms of post-traumatic stress disorder (PTSD) associated with COVID-19, and symptoms of depression.

\section{Results}

1140 people entered the research site and agreed to answer the questionnaire. $73.2 \%$ of the participants were women, $34.2 \%$ were 22 years old while the Department of Education and Social Work has the largest percentage of participants (22\%). It is followed by the Department of Preschool Education and Education (16.3\%), while several students are driven by the Department of Medicine (8.9\%). $68.0 \%$ of participants reported moderate subclinical stress symptoms, which means that the Covid-19 virus initially appeared to affect students' stress levels. $28.2 \%$ and $32.3 \%$ of the participants reported mild and moderate symptoms of depression, respectively, while $25.0 \%$ reported severe symptoms of depression as indicated by their BDI scores. The highest incidence of moderate depression symptoms is found at the age of 24 , while the highest incidence of severe depressive symptoms is at the age of 25 years. $83.1 \%$ of the participants showed clinically significant PTSD symptoms associated with COVID-19. At a 5\% significance level, gender appears to have a statistically significant effect on depression, as $\mathrm{p}=0.048$ $(<0.05)$ and $r=0.062$. In contrast, there does not appear to be a statistically significant association between gender and subclinical symptoms of stress and psychotraumatic stress, since $\mathrm{p}=0.190(>0.05), \mathrm{r}=0.041$ and $\mathrm{p}=0.474(>0.05), \mathrm{r}=0.022$ respectively. While it is observed that there is no moderate or high correlation between subclinical symptoms, depression and psychotraumatic stress symptoms (Table 1).

Table 1: A correlation matrix showing intercorellations between the total scores of the three variables (subclinical symptoms, depression and psychotraumatic stress symptoms)

\begin{tabular}{|c|c|c|c|c|}
\hline & & SSQ-25 & BDI & IES-R \\
\hline \multirow[t]{3}{*}{ SSQ-25 } & Pearson Correlation & 1 &,- 024 & ,020 \\
\hline & Sig. (2-tailed) & & 445 &, 516 \\
\hline & $\mathrm{N}$ & 1040 & 1040 & 1040 \\
\hline \multirow[t]{3}{*}{ BDI } & Pearson Correlation &,- 024 & 1 & ,006 \\
\hline & Sig. (2-tailed) & 445 & & 847 \\
\hline & $\mathrm{N}$ & 1040 & 1040 & 1040 \\
\hline \multirow[t]{3}{*}{ IES-R } & Pearson Correlation & ,020 & ,006 & 1 \\
\hline & Sig. (2-tailed) &, 516 & ,847 & \\
\hline & $\mathrm{N}$ & 1040 & 1040 & 1040 \\
\hline
\end{tabular}




\section{Discussion}

Studies have suggested that public health emergencies can have many psychological effects on university students, which can be expressed as anxiety, fear, and worry, depression, among others (Mei et al., 2011; Konstantopoulou \& Raikou, 2020; Kaparounaki et al., 2020). The aim of this study was to assess the psychological state of college students during an epidemic. This study showed that $68.0 \%$ of students reported moderate subclinical anxiety symptoms, meaning that the COVID-19 virus initially appeared to affect students' stress levels. $28.2 \%$ and $32.3 \%$ of students reported mild to moderate symptoms of depression, respectively. Student anxiety may be due to the gradually increasing distances between people resulting from quarantine. It is known whether anxiety disorders are more likely to occur and worsen in the absence of interpersonal communication (Xiao, 2020; Kmietowicz et al., 2020). Very important of the findings is that $83.1 \%$ of the students experienced clinically significant PTSD symptoms that appear to be related to COVID-19. Gender does not seem to have a statistically significant effect on depression, while there does not appear to be a statistically significant relationship between gender and subclinical symptoms of anxiety and traumatic stress.

\section{Conclusion}

Quarantine and social distance, in combination with the continuing threat posed by the pandemic, provoke negative emotions. Especially for the university students, who are going through a period of transition associated with developmental challenges, increased levels of psychological distress are expected.

As mentioned above, we believe that the recording of student psychology during the COVID-19 pandemic is important in order to outline the psychology of students, which will contribute to the proper and timely preparation of psychological support centers to meet their immediate needs.

Overall, it should be noted that in our study even though there were no signs of significant correlation between the three variables, the student population was affected psychologically by the pandemic outburst of COVID-19, since tendencies of subclinical anxiety and depression were reported. Future studies should address the issue of reevaluating these tendencies, soon after the spread of the disease has been taken under control.

\section{References}

American Psychiatric Association (2013). Diagnostic and statistical manual of mental disorders (5th edition). Arlington (VA): American Psychiatric Association. 
Asukai, N., Kato, H., Kawamura, N., Kim, Y., Yamamoto, K., Kishimoto, J., Miyake, Y., \& Nishizono-Maher, A. (2002). Reliability and validity of the Japanese language version of the Impact of Event Scale-Revised (IES-R-J): Four studies of different traumatic events. Journal of Nervous and Mental Disease, 190 (3), 175-182.

Barbisch, D., Koenig, K. L., \& Shih, F. Y. (2015). Is There a Case for Quarantine? Perspectives from SARS to Ebola. DOI: https://doi.org/10.1017/dmp.2015.38. Cambridge University Press. Available: https://doi.org/10.1017/dmp.2015.38

Bayram, N., \& Bilgel, N. (2008). The prevalence and socio-demographic correlations of depression, anxiety and stress among a group of university students. social psychiatry. Psychiatric Epidemiology, 43, 667-672.

Beck, A. T. (1972). Depression: Causes and Treatment. Philadelphia: University of Pennsylvania Press. ISBN 0-8122-1032-8, doi:10.1007/s00115-016-0181-2.

Cao, W., Fang, Z., Hou, G., Han, M., Xu, X., Dong, J., \& Zheng, J. (2020). The psychological impact of the COVID-19 epidemic on college students in China. Psychiatry research, 287, 112934. Available: https://doi.org/10.1016/j.psychres.2020.112934

Centers for Disease Control and Prevention (2020). Coronavirus Disease 2019 (COVID-19): Interim Guidance for Administrators of US Institutions of Higher Education. (March 18, 2020) https://www.cdc.gov/coronavirus/2019-ncov/community/guidance-iheresponse.html

Eisenberg, D., Gollust, S. E., Goldberstein, E., \& Hefner, J. L. (2007). Prevalence and correlates of depression, anxiety and suicidallity among university students. American Journal of Orthopsychiatry, 77(4), 534-542.

Grubic, N., Badovinac, S., \& Johri, A.M. (2020). Student mental health in the midst of the COVID-19 pandemic: A call for further research and immediate solutions. International Journal of Social Psychiatry, DOI: 10.1177/0020764020925108

Helms, E., Wetzel, E., \& Weierstall, R. (2017). Development and validation of the Subclinical Stress Symptom Questionnaire SSQ-25. Der Nervenarzt, 88(9), 10501057.

Kaparounaki, C. K., Patsali, M. E., Mousa, D.-P. V., Papadopoulou, E. V. K., Papadopoulou, K. K. K., Fountoulakis, K. N. (2020). University students' mental health amidst the COVID-19 quarantine in Greece. Psychiatry Research, 290, https://doi.org/10.1016/j.psychres.2020.113111

Karalis, T. \& Raikou, N. (2020). Teaching at the times of COVID-19: Inferences and implications for higher education pedagogy International Journal of Academic Research in Business and Social Sciences, 10(5), 479-493.

Karalis, T. (2020). Planning and evaluation during educational disruption: Lessons learned from COVID-19 pandemic for treatment of emergencies in education. European Journal of Education Studies, 7 (4), 125-142.

Kmietowicz, Z., (2020). Rules on isolation rooms for suspected covid-19 cases in GP surgeries to be relaxed. BMJ, 368, m707. 
Konstantopoulou, G. \& Raikou, N. (2020). Clinical evaluation of depression in university students during quarantine due to covid-19 pandemic. European Journal of Public Health Studies, 3(1), 1-8.

Liu, S., Yang, L., Zhang, C., Xiang, Y.T., Liu, S., Hu, S., Zhang, B., (2020). Online mental health services in China during the COVID-19 outbreak. Lancet Psychiatry. Available: https://doi.org/10.1016/S2215-0366(20)30077-8.

McCabe, D. (2019). The Impact of Event Scale - Revised (IES-R). New York University Rory Meyers College of Nursing, 19. Available: https://consultgeri.org/try-this/generalassessment/issue-19.pdf

Mei S. L., Yu J. X., He B. W., Li J. Y. (2011). Psychological investigation of university students in a university in Jilin province. Med Soc (Berkeley), 24(05), 84-86.

National Public Health Organization (May 15, 2020). Coronavirus disease (COVID-19) Important News. Available: https://eody.gov.gr/en/covid-19/

Papadioti-Athanasiou, V., \& Kaltsouda, A. (2007). Epidemiological study of students' mental health (The case of University of Ioannina). In T. Giovazolias, E. Karademas, \& A. Kalantzi-Azizi (Eds.), FEDORA-PSYCHE. Crossing Internal and External Borders: Practices for An Effective Psychological Counselling in The European Higher Education. Athens: Ellinika Grammata.

Sawatzky, J. V. (1998). Understanding nursing students' stress: a proposed framework. Nurse Education Today, 18, 108-115.

Skai News (March 10, 2020). Coronavirus: All schools and universities of the country are closing for 14 days. Available: https://www.skai.gr/news/greece/tsiodras-eody-koronoios

University of Patras (April 30, 2020). Psychological support for all university community members - COVID-19. Press Release 29/2019-2020. Available: https://www.upatras.gr/el/node/9181

University of Patras COVID-19 Committee (April 8, 2020). Second Report of the Committee for the education in the University in COVID-19 situation [in Greek]. Available: https://eclass.upatras.gr/courses/EE994/

Weiss, D. S., \& Marmar, C. R. (1997). The Impact of Event Scale-Revised. In J. P. Wilson, \& T. M. Keane (Eds.), Assessing Psychological Trauma and PTSD: A Practitioner's Handbook (pp. 399-411). New York: Guilford Press.

Williams, B. (2020). Mental health concerns arise amid COVID-19 epidemic. Psychiatry Advisor, February 26, 2020. Available: https://www.psychiatryadvisor.com/home/topics/general-psychiatry/mentalhealth-concerns-arise-amid-covid-19-epidemic/.

Xiao, C., 2020. A novel approach of consultation on 2019 novel coronavirus (COVID-19)Related psychological and mental problems: structured letter therapy. Psychiatry Investig. 17 (2), 175-176.

Yang, Y., Li, W., Zhang, Q., Zhang, L., Cheung, T., \& Xiang, Y.T. (2020). Mental health services for older adults in China during the COVID-19 outbreak. Lancet Psychiatry. Available: https://doi.org/10.1016/S2215-0366(20)30079-1. 
Author(s) will retain the copyright of their published articles agreeing that a Creative Commons Attribution 4.0 International License (CC BY 4.0) terms will be applied. Under the terms of this license, no permission is required from the author(s) or publisher for members of the community to copy, distribute, transmit or adapt the article content, providing a proper, prominent and unambiguous attribution to the authors in a manner that makes clear that the materials are being reused under permission of a Creative Commons License. Views, opinions, and conclusions expressed in this research article are views, opinions, and conclusions of the author(s). Open Access Publishing Group and European Journal of Public Health Studies shall not be responsible or answerable for any loss, damage, or liability caused to/arising out of conflicts of interest, copyright violations, and inappropriate or inaccurate use of any kind content related or integrated into the research work. All the published works are meeting the Open Access Publishing requirements. They can be freely accessed, shared, modified, distributed, and used in educational, commercial, and non-commercial purposes under a Creative Commons Attribution 4.0 International License (CC BY 4.0). 